\title{
UP PICTURA POESIS: REFLEXIONES DESDE EL TEATRO DE SHAKESPEARE
}

\section{Natalia Carbajosa Palmero}

\author{
Universidad Politécnica de Cartagena \\ natalia.carbajosa@rec.upct.es
}

The fixture of her eye has motion in't, As we are mocked with art. Leontes en Winter's Tale, V, 3.

\section{INTRODUCCIÓN}

La semiótica lleva ya décadas nutriendo a la teoría teatral respecto a los distintos niveles de comunicación múltiple y simultánea, tanto lingüística como visual, que se producen durante la representación de una obra, así como respecto a las implicaciones que dicha comunicación tiene en la recepción de la obra a lo largo de los siglos. Hoy día sería inimaginable, por ejemplo, abordar un análisis del texto dramático sin 
los tres tipos de signos teatrales que Peirce (1974) definió como iconos, índices y símbolos; o sin prestar atención a los distintos planos referenciales, donde la deixis supera los límites de lo puramente textual o endofórico, «for theatre discourse possesses and articulation that is supplementary to the double articulation already present in any other form of discourse» (Issacharoff, 1989: 8), para hacerse plenamente ostensiva; o sin tener en cuenta la duplicidad del mensaje emitido desde el proscenio, que está necesariamente fragmentado entre los personajes y sin embargo llega completo al patio de butacas, convirtiendo a la ironía en el principal aliado para la interpretación que estos últimos deben hacer de lo que ocurre ante sus ojos (Serpieri, 1991: 119-143).

Considerada desde un punto de vista más amplio, la semiótica teatral ofrece nuevas posibilidades al interactuar con otros códigos artísticos; posibilidades que se traducen, si cabe, en una mayor comprensión hacia el acto comunicativo representado en la escena. Este artículo se propone explorar la relación entre el teatro de Shakespeare y las artes visuales, tanto a partir del concepto de la imagen imperante en el Renacimiento como desde los presupuestos artísticos del siglo $\mathrm{XX}$ que más han ahondado en la teoría de los signos.

\section{LA IMAGEN EN EL RENACIMIENTO}

\subsection{El teatro}

El Renacimiento italiano inaugura un nuevo concepto de las artes visuales, sobre todo la pintura y la escultura; este nuevo concepto va más allá de las definiciones medievales tradicionales, tanto derivadas del latín (ars) como del griego (techné), en las que predominaba la consideración de las habilidades técnicas y la función didáctica de estas disciplinas frente a su valoración estética. Junto a la escasa apreciación del arte visual per se, la Edad Media expresa una importante veneración por las artes literarias, en parte por su restringida accesibilidad, que las convierten en un objeto sólo al alcance de los eruditos, y en parte por la creencia, desde tiempos pasados, en la capacidad de la poesía para contar las hazañas del pueblo o transmitir verdades divinas. El Renacimiento, al rescatar a la pintura y la escultura de su función adoctrinadora, por un lado, y acercar la letra impresa a las clases 
sociales no estrictamente eruditas, por otro, no sólo sitúa a ambas formas estéticas en un plano similar, sino que además inaugura la posibilidad de establecer un constante parangón entre ambas:

\begin{abstract}
Writers in the early Middle Ages had ridiculed the pretensions of art, painting in particular, to 'ape' the products of nature; writers in Shakespeare's time see Art and Nature contending on equal, or seemingly equal, terms. [...] There was reciprocal influence of literary humanism and the visual arts [...] as summed up in the Renaissance commonplace, ut pictura poesis (Salingar, 1986: 4-5).
\end{abstract}

Como no podía ser de otra manera, la comparación constante que desde este momento se establece entre pintura y poesía encuentra un amplio abanico de expresión en el único género literario en que la palabra y la imagen comparten protagonismo: el teatro. Dicha comparación se realiza, además, en ambas direcciones: de la pintura a la escena, y viceversa. En efecto, la nueva forma de representar el mundo sobre el lienzo, mimética, narrativa y dinámica, hace que teóricos como Leonardo Da Vinci la definan como una verdadera evocación dramática, cuyo fin último sería la representación y la observación de los estados mentales de sus protagonistas (Gombrich, 1987: 87). Esta característica del arte pictórico del Renacimiento tiene su precedente, un siglo antes, en el arte gótico, en el que observamos, sobre todo de la mano de artistas como Giotto, una técnica pictórica en la que:

[...] la representación de escenas bíblicas o hagiográficas depende de la actitud dramática y la expresión del gesto de los actores, de forma que los personajes que protagonizan la acción pueden hacerla verosímil por la inmediatez de su naturalidad (Murray, 1995: 17).

El epíteto teatral, asimismo, puede llegar a tener un matiz despectivo cuando se aplica a la pintura, esto es, cuando el énfasis en el decorum arremete contra los excesos grandilocuentes que no sólo eran patrimonio de la literatura. En cualquier caso, el acercamiento de ambas artes inaugura (y esto es lo que nos interesa) una nueva manera de mirar. Hulse (1990), en un interesante estudio comparativo, ofrece un ejemplo extraído del Canto XXXIII de Orlando Furioso: el dueño del castillo muestra a sus invitados su colección de pinturas y tapices, intercalando las descripciones pictóricas y las referencias a la calidad artística de las mismas con retazos de la heroica historia a la 
que hacen referencia, y que es la historia del propio castillo y de la familia del anfitrión. Esta experiencia pictórica colectiva se asemeja poderosamente a la del público asistente a una función teatral, y además se revela como tremendamente moderna, no sólo por la importancia que se le concede a la presencia del público espectador, sino sobre todo por el papel activo que desempeña a la hora de establecer un diálogo con el cuadro que observa:

This is ritualized group consumption in which the viewing of paintings is a theatrical and social experience, opposite in every way to our solitary and silent vigils in front of the designated artifacts hung in museums (Hulse, 1990: 1).

La comparación entre pintura y teatro funciona, como es lógico, en la otra dirección. La principal cualidad visual del teatro es su naturaleza ostensiva, es decir, la acción de mostrar en lugar de narrar, presentar el objeto directamente ante el público en lugar de describirlo. La ostensión teatral descansa, sobre todo, en una presentación icónica de los signos. Recordemos que el icono, en pintura, establece una relación de semejanza entre el objeto real y su representación visual. Así, el escenario se convierte en una representación de la calle, la corte, la iglesia o cualquier escenario de la vida real, y sus personajes, en representaciones de jueces, reyes, nobles o plebeyos reales. Incluso cuando el escenario adquiere proporciones simbólicas (el símbolo, como sabemos, establece una relación arbitraria entre el objeto y su representación), está siendo icónicamente fiel a una realidad en la que los símbolos, tan arraigados en conceptos como la monarquía o la religión, o desarrollados en géneros pictórico-literarios como los emblemas, forman parte del inconsciente colectivo de la vida cotidiana. Esta cualidad visual del teatro, como es lógico, se pone al servicio del público, único intérprete posible de las imágenes que la escena le proporciona. De nuevo, la comparación entre ambos géneros es inevitable:

It is perhaps no mere accident that a playwright should derive his sense of audience participation from the analogous attitude of someone looking at a painting (Faas, 1986: 74).

La relación del teatro con la imagen, sin embargo, alcanza mucha más profundidad cuando éste renuncia a la iconicidad visual, hasta cierto punto esperable y por tanto no muy novedosa, y la transforma 
en una iconicidad verbal. Es decir: la palabra se convierte en el vehículo mediante el cual se nos transmite una imagen o descripción (hipotiposis), ya sea de un lugar (topografía), una característica física o moral de un ser animado (prosografía y etopeya), una situación (tableau vivant), etc. La cualidad principal de este recurso, de proporciones claramente retóricas, consiste en la capacidad de la descripción para presentar las cosas no de una manera neutral sino vívida, cargada de sentido, implicaciones, movimiento, y capaz de llegar y de conmover al público; su conceptualización clásica se realiza a través del término griego de enargeia (latín evidentia o raepresentatio). El fin último, sin duda, es el de persuadir de una manera más sutil, y al mismo tiempo más efectiva, que sólo a través de la imagen, pues la representación verbal permite al hablante manipular la versión de dicha imagen a su antojo. La riqueza del arte teatral, aunando palabra y visión, está servida:

For the Elizabethans the 'pictorial' use of words constituted a well-defined rhetorical game much recommended for its efficacy as a locutionary coup upon the ear and the mind's eye (Elam, 1984: 61).

En las obras de Shakespeare son constantes las pinturas con palabras; no sólo por la ausencia de decorados, que convierten a las descripciones de ciudades y bosques en verdaderos ejercicios de iconicidad verbal, sino también en la descripción anticipada de personajes que van a aparecer más tarde, con lo cual se generan una serie de expectativas en el espectador, o en la relación de hechos que no se presentan en escena. Así, por ejemplo, resulta ya clásico hablar de la descripción que Biondello hace de Petruchio en The Taming of the Shrew, cuando la boda entre Petruchio y Kate va a celebrarse y todos esperan impacientes la llegada de éste:

Why, Petruchio is coming in a new hat and an old jerkin; a pair of breeches trice turned; a pair of boots that have been candle-cases, one buckled, another laced; an old rusty sword tane out of the town armoury, with a broken hilt and chapeless; with two broken points; his horse hipped... (III, 2: 41-45).

La detallada descripción de la absurda indumentaria de Petruchio genera, sin duda alguna, una disposición cómica en el patio de butacas que llegará al clímax en la aparición real del personaje. El paso previo, 
pues, ha sido despertar los estímulos de la imaginación. Algo similar ocurre en la famosa descripción que Dromio de Siracusa hace de la cocinera de la casa de Antipholus en The Comedy of Errors, personaje que ni siquiera tiene un papel real (no aparece en la obra) y que, sin embargo, ha quedado virtualmente plasmada en la memoria de los espectadores para siempre:

Syr. Ant. What complexion is she of?

Syr. Dro. Swart like my shoe, but her face nothing like so clean kept; for why? She sweats, a man may go over-shoes in the grime of it.

(...)

Syr. Ant. Then she bears some breath.

Syr. Dro. No longer from head to food than from hip to hip; she is spherical, like a globe; I could find out countries in her (III, 2: 99-113).

Evidentemente, la descripción hiperbólica genera la máxima comicidad posible por el mismo hecho de que no podamos contrastar lo que Dromio nos pinta a través de sus palabras con una imagen real.

La equiparación de la literatura y la pintura como formas de ficción paralelas también la encontramos reflejada en las comedias, normalmente enfrentadas, por su naturaleza icónica (copia de la realidad), a la realidad misma, que ofrece siempre el modelo, si no más perfecto, sí al menos el más auténtico. Así, oímos a la princesa de Francia en Love's Labour's Lost rechazar los cumplidos de Boyet de esta manera:

Good Lord Boyet, my beauty, though but mean,

Needs not the painted flourish of your praise:

Beauty is bought by judgment of the eye,

Not utter'd by base sale of chapmen's tongues (II, 1: 13-16).

Donde painted flourish alude precisamente a esa pintura con palabras que, por muy brillante que sea, no pasará de mera imitatio. En un sentido parecido, Boyet exclama, en el transcurso de la misma obra, lo siguiente: Fie, painted rhetoric! O! She needs it not (IV, 3); la retórica, cómo no, es parte esencial de este argumento compartido entre las dos artes y la realidad. Y Orlando, en As You Like It, desecha el discurso manido de Jacques y su mal du siècle llamándolo painted cloth, confiriendo a la pintura, referida al discurso, la cualidad de disfraz, cliché, imitación en el peor sentido. 
También en las páginas shakesperianas encontramos descripciones de cuadros, al estilo de la que considerábamos en Orlando Furioso. En el prólogo de The Taming of the Shrew, donde Sly es sometido a un engaño y obligado a presenciar la obra junto con el resto de los espectadores, la decoración pictórica se considera un elemento esencial de su peculiar inmersión en la piel de un noble:

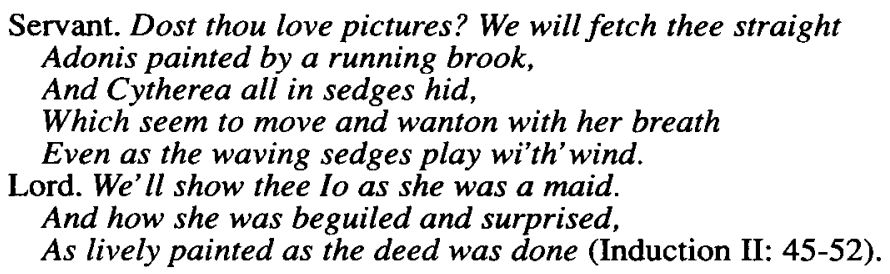

En esta descripción encontramos todos los elementos típicos del ideario artístico del Renacimiento: representación de una acción con personajes reales o ficticios, a menudo (como en este caso) mitológicos, que se mueven en un espacio real y concreto y protagonizan un suceso determinado (Adonis corriendo por un puente, Cytherea entre los juncos, Io raptada por Júpiter que aparece entre la niebla). Esta técnica parte de un principio de observación opuesto al inmovilismo medieval: los objetos se mueven y se relacionan en el espacio como si de un escenario se tratara. Tanto si Shakespeare tiene en mente cuadros reales, como si está simplemente transcribiendo las narraciones de Ovidio, no hay duda de que su relación artística es plenamente renacentista.

Así pues, Shakespeare no sólo es consciente del juego de equiparación entre las artes, su naturaleza imitativa y las posibilidades expresivas que genera la sustitución de una por otra (generalmente, la palabra en lugar de la imagen), sino que multiplica sus efectos repetidamente en el escenario, de manera que el público recibe de forma simultánea dos códigos principales (lingüístico y visual) e indivisibles: no es posible separar dónde termina uno y comienza el otro.

\subsection{La teoría visual renacentista}

La imagen, tal y como es representada en el arte pictórico renacentista, supone no sólo una nueva manera de mirar, sino ante todo una 
nueva consideración del arte, y para algunos, el primer momento de la civilización europea en que el arte existe como parte de la vida y de la realidad (Debray, 1994). Así, frente al arte medieval, indicial y revelador en su forma (cada manifestación artística lleva implícita la presencia de Dios) y anónimo en su ejecución y valoración, el arte renacentista, icónico (cada obra es un reflejo de la realidad, y por tanto una forma legítima de conocimiento) y concreto, define al hombre como creador y como espectador, es decir, pone un sujeto (el hombre) contemplando un objeto (la obra). Sólo esta nueva actitud pictórica puede explicar, por ejemplo, el desarrollo de la perspectiva, y su voluntad de reproducir imágenes, durante todo el Renacimiento, tal y como las vería el ojo humano en un recorrido visual por un paisaje real. Conocedor, sin duda alguna, de las técnicas pictóricas modernas, Shakespeare rinde un verdadero homenaje a la visión en perspectiva en la descripción de las colinas de Dover que Edgar evoca para Gloucester ciego en King Lear, tal y como distintos autores han señalado, y que constituye ya un ejemplo clásico de esta pintura con palabras con auténtico sello renacentista.

Al margen de consideraciones técnicas, la imagen del Renacimiento constituye también una nueva actitud conceptual respecto al acto de ver, que por primera vez en la historia ( $y$ hasta nuestros días) hace referencia a otros términos como conocer, en el sentido más intelectual, además de empírico, de la palabra:

"Seeing" has by metonimy come to denote far more than physical eyesight; it suggests virtually all of our perceptions as well as the ways in which we understand and organize our perceptions. Sight, insight, and vision are metaphorically basic to the language we use when we think about thought (Frye, 1980: 323).

Esta nueva manera de ver, de metaforizar el conocimiento a través de la imagen, se equipara en el teatro con el conocimiento a través de la palabra. Los personajes en escena, a través de sus diálogos, pero también a través de sus gestos, trajes, movimientos, etc., realizan una verdadera depiction of life; más allá de la realidad misma, es la ilusión del arte, basada en la confluencia de imagen y palabra (claramente en el teatro, pero como hemos visto, también en el caso de la pintura, donde se entabla un verdadero diálogo entre el cuadro y el espectador), la que devuelve al hombre una verdadera perspectiva sobre sí mismo y sobre lo que le rodea. 
En las obras de Shakespeare, el conocimiento intuitivo que se revela a través de la imagen es, sobre todo, el que da lugar al enamoramiento (lo que vulgarmente conocemos como amor a primera vista). El propio término que a veces designa al amor, fancy, es también sinónimo de imaginación, es decir, describe el movimiento por el que imaginamos a través de lo que vemos (the mind's eye); así le ocurre a Olivia en Twelfth Night, después de ver a Viola disfrazada de Cesario:

Olivia. I do I know not what, and fear to find

Mine eye too great a flatterer for my mind (I, 5: 332-333).

Invirtiendo los efectos del tándem imagen-imaginación, Helena, en Midsummer Night's Dream, argumenta cómo es ésta última, y no lo que realmente vemos, la causante de los desvaríos amorosos:

Helena. Love looks not with the eyes, but with the mind

And therefore is wing'd Cupid painted blind (I, 2: 235-236).

En cualquier caso, lo importante es que por primera vez el arte, en sus diferentes formas de expresión (la ficción), se privilegia en el mundo real como forma de conocimiento sensible.

\subsection{Peculiaridades del contexto isabelino}

Aunque Shakespeare conoce y utiliza verbalmente, tal y como acabamos de señalar, las nuevas técnicas de composición y visión pictórica como la perspectiva, el modelo artístico más cercano a su ámbito de creación, el isabelino, difiere en gran medida de la estética italiana que se iba imponiendo en el resto del continente. En efecto, la pintura inglesa perpetúa aún durante casi un siglo formas de composición típicamente medievales; así, frente a la perspectiva y la creación de un fondo del cuadro (y con ello, de unidad de visión y acción), conserva la apariencia de un fondo vacío y plano, exento de importancia a no ser por algunos detalles de contenido simbólico. Junto a esto, observamos otras técnicas no evolucionadas como la multiplicidad de acciones simultáneas (en un solo cuadro, por ejemplo, se podía contar la vida de 
un personaje ilustre, desde su nacimiento hasta su muerte), así como una gran fastuosidad en el vestido y complementos de los personajes retratados, sin duda para compensar la ausencia de fondo. Existe una conexión más que evidente entre esta técnica artística y la organización del escenario en el teatro isabelino, donde frente a una ausencia casi absoluta de decorados, predomina el ornato excesivo de los trajes; ambas prácticas, propias de la sociedad inglesa, condicionan una particular manera de mirar y de organizar el mundo de la ilusión, que Shakespeare supo aprovechar, como siempre, a su manera:

Such and uncluttered stage not only can free the audience's attenttion for nuances of poetry but can also free the eye from distraction so that it can focus upon the actors. [...] In short, here is a stage that can heighten both verbal and visual language (Dessen, 1977: 28).

A la palabra se le concede, pues, una capacidad descriptiva sin precedentes. Más aún, al haber renunciado previamente a una puesta en escena icónica, las posibilidades de moverse en el mundo de ficción se multiplican: no necesita mantener una apariencia de realidad aquel ámbito que desde un principio no pretende tal cosa.

La importancia del traje frente al escenario merece sin embargo otro tipo de reflexión; según Mowat (1981: 73), éste presenta dos funciones principales en el teatro isabelino: una simbólica (el color, la disposición), mediante la cual se envían mensajes a los espectadores acerca del estado de ánimo de los personajes, y otra ilusoria (el tipo de traje, el tejido), que hace referencia al rango y papel de quien así va vestido. En la mejor tradición shakesperiana, sin embargo, se introduce un tercer matiz de naturaleza dialéctica; así, frente a la ostensión absoluta del traje en su doble significación, las intervenciones del personaje que lo lleva pueden negar o corroborar lo que dicho traje, en principio, comunica:

In London drama [...] clothing sends messages not about how we can expect a character to behave, but rather about his status. [...] The way is open, then, for plays in which the character's actions and his growth can be placed within or against the costume he wears.

$\mathrm{Si}$, por tanto, el escenario vacío permite al lenguaje ejercer como creador de ese espacio visual ausente, la preeminencia visual del traje 
en relación con quien lo lleva le concede a éste posibilidades argumentativas más allá de lo que vemos. El teatro isabelino presenta así su propia versión y adaptación del ut pictura poesis en su doble vertiente. Shakespeare, fascinado sin duda por esta intromisión de la imagen en la palabra y viceversa, no es ajeno, en sus obras, al juego constante que ambas le proporcionan desde su misma tradición en Inglaterra.

\section{DEL RENACIMIENTO AL SIGLO XX}

Precisamente en el recién acabado siglo XX, y no antes, los distintos periodos de la historia del hombre reciben designaciones a través de las cuales se señalan cambios de importancia. El momento llamado Renacimiento marca a su vez el comienzo de la denominada modernidad, caracterizada, según el espíritu humanista, por el descubrimiento del hombre como el centro de todas las cosas y el verdadero descubridor de las mismas. Lo llamativo de este consabido argumento es que muchos pensadores ejemplifican esta nueva forma de sentir y percibir el mundo a través de las artes visuales, y no a través de los numerosos escritos teóricos de la época. La metáfora de la imagen se revela una vez más como imprescindible en el fondo de la cuestión. No se trata, sin embargo, de que el hombre simplemente haya pasado a ser protagonista de la representación pictórica, desplazando a la divinidad; el meollo del asunto lo constituye la relación que el hombre-espectador establece con aquello que ve y de lo que es a su vez protagonista; más aún, para que sea efectiva, dicha relación ha de ser de ida y vuelta, es decir, del cuadro al espectador, como si de un espectáculo teatral se tratara:

Todo arte que sólo tenga dos dimensiones, la de la obra y la del espectador, sólo puede crear una platitude, puesto que no es más que la captación de un espectáculo-vitrina por un pintor-mirón. La profundidad sólo nace en el momento en que el espectáculo mismo vuelve lentamente su sombra hacia el hombre y comienza a mirarle (Barthes, 1983: 3334).

Profundidad, fondo, perspectiva, son palabras clave de esta nueva forma de percepción estética, que se revela además tremendamente 
activa. Para Foucault (1994), que constata este fenómeno a través de Las Meninas de Velázquez por su condición de reciprocidad, de cuadro-espejo (los personajes del cuadro miran a quien a su vez los contempla), es la prueba patente de que el arte renacentista y barroco, tanto visual como literario, mantiene una relación de semejanza (icónica) con la realidad de la que parte. Según éste, y a pesar de la ya debatida separación entre las palabras y las cosas que comienza con el Renacimiento y culmina en el siglo XVII, el lenguaje como sistema de signos presenta en esta época una cualidad ternaria que va más allá de la relación binaria significante-significado, constituyendo precisamente el tercer término de la relación la semejanza entre la realidad y su designación a través del lenguaje. La literatura renacentista, que busca modelos en el hombre y su entorno, confirma la función significativa del lenguaje. La literatura contemporánea, alejada de y muchas veces opuesta al modelo representacional y a la posición central del hombre en el mismo, ofrece alternativas a dicha función significativa. Lo que nos interesa, por una parte, es constatar esa función central del hombre, sujeto y objeto, real y representado, en todas las formas de conocimiento renacentistas:

The Elisabethan world-picture thus depends upon what we might term a spectator consciousness, an epistemological model based upon an observer who stands outside of what she sees and in a position of mastery over it (Freedman, 1991: 9).

Y reflexionar, por otra, acerca del diferente soporte semiótico que sustenta esa estética representacional, frente a la que conocemos a finales del siglo XX. Dicha diferencia obedece, según los teóricos, a un cambio en los modos de significación, y por ende, de su relación con la realidad significada. Así, frente al icono renacentista, que tiene lo real por referente, la época contemporánea aboga por el símbolo, que sólo es referente de sí mismo; la imagen, por su inmediatez y su nuevo estatus semiótico, que supera las barreras vida / arte levantadas por el Renacimiento, ha sustituido a la realidad:

Suprimir la re de la representación, hacer la realidad o la vida autoimaginantes. A través del ready-made $o$ del happening el artista se esfuerza en remontarse hasta la bifurcación salvaje/civilizado. Superar el «corte semiótico" [...] Abolir el marco del cuadro, e incluso el cuadro mismo como superficie diferenciada (Debray, 1994: 61). 
La abolición de los límites de lo representado, a pesar de su intención de vuelta a los orígenes (cuando el arte se identificaba plenamente con la realidad por la función social que cumplía dentro de ésta) tiene, como sabemos, patentes resultados de confusión semiótica, mayores cuanto más nos adentremos en el mundo informático y virtual. La tecnología se alía con la imagen, de manera que sólo lo que vemos es lo que tomamos como real, cuando verdaderamente estamos sustituyéndolo.

El código estético actual presenta otro tipo de inversión semiótica respecto al renacentista. Pensemos en los espectadores que acudían al teatro isabelino, herederos de unos modos de recepción artística medievales, es decir, colectivos, sociales, y en los solitarios consumidores de cualquier manifestación cultural de hoy, incluidas las que reúnen un número elevado de personas en una sala (cine, teatro, ópera, museos). El arte pierde su función social y se convierte en una experiencia individual y afectiva, lo que multiplica sus manifestaciones al tiempo que dispersa su valor. Su codificación en la conciencia colectiva también está trazada a la inversa. En el Renacimiento, la naturaleza (humana y natural) ofrece modelos que el arte reproduce. En un mundo como el nuestro, donde todos los límites naturales (ríos, bosques) han experimentado una acotación humana y una clarificación científica, donde los fugitivos de la sociedad no irían a refugiarse al bosque de Arden, sino entre los barrios anónimos de una megalópolis, es lo social lo que ofrece modelos susceptibles de convertirse no sólo en cauces artísticos, sino también en instrumentos definitorios de una mitología moderna:

El mito consiste en hacer de la cultura naturaleza, o al menos convertir en "natural» lo social, lo cultural, lo ideológico, lo histórico... los fundamentos totalmente contingentes del enunciado, bajo el efecto de la inversión mítica, se convierten en el Sentido Común, el Derecho Común, la Norma, la Opinión Común... (Barthes, 1987: 83).

Observamos de este modo cómo lo contingente se convierte en absoluto (aunque siempre sujeto a las fluctuaciones arbitrarias de la sociedad). Y es que, donde los límites arte / vida se han vuelto imprecisos e inclasificables (aunque sin capacidad para volver a reconstruir la estética del hombre pre-social) y la tecnología explota las posibilidades de esa nueva tierra de nadie de significación virtual, el hombre sigue necesitando puntos de referencia estables, signos a los que aferrarse. 


\section{CONCLUSIÓN}

El legado de la antiguiedad clásica, tamizado por el medievo cristiano, nos ha brindado un espectáculo teatral renacentista de características propias a través de sus dos presupuestos teóricos principales, a saber, el lenguaje y el arte. La semiótica teatral, abriéndose al diálogo entre la imagen y la palabra y ubicándose tanto en el Renacimiento como en el pasado inmediato, puede sin duda arrojar luz respecto a futuras maneras de mirar. En esto, Shakespeare continúa siendo un paradigma del uso de la metáfora visual en todas las direcciones posibles, y revelándose completamente vigente a la hora de analizar nuestras propias reacciones respecto al arte, a los discursos que articulan su relación con la realidad, y a nuestra postura como espectadores de las obras de todos los tiempos.

\section{Referencias bibliográficas}

BARTHES, R. (1983). Ensayos críticos. Barcelona: Seix Barral. - (1987). El susurro del lenguaje. Barcelona: Paidós.

DEBRAY, R. (1994). Vida y muerte de la imagen: historia de la mirada en Occidente. Barcelona: Paidós.

Dessen, A. (1997). Elizabethan Drama and the Viewer's Eye. Chapel Hill: University of North Carolina Press.

Elam, K. (1984). Shakespeare's Universe of Discourse. Cambridge University Press.

FAAS, E. (1986). Shakespeare's Poetics. Cambridge University Press.

Foucault, M. (1994). The Order of Things: An Archaeology of Human Sciences. London: Routledge.

FrEedMAN, B. (1991). Staging the Gaze: Postmodernism, Psychoanalysis and Shakespearean Comedy. Ithaca: Cornell University Press.

FRYE, R. M. (1980). «Ways of Seeing Shakespearean Drama and Elizabethan Painting». Shakespeare's Quaterly 30, 323-342.

GoMBrich, E. H. (1987). La imagen y el ojo. Madrid: Alianza.

Hulse, C. (1990). The Rule of Art: Literature and Painting in the Renaissance. University of Chicago Press.

Issacharof, M. (1989). Discourse as Performance. Stanford University Press.

MowAT, B. A. (1981). "“The Getting Up of the Spectacle": The Role of the Visual on the Elizabethan Stage, 1576-1600». En The Elizabethan Theatre, G. R. Hibbard (ed.), 70-86. Ontario: P. D. Meany. 
UT PICTURA POESIS: REFLEXIONES DESDE EL TEATRO DE SHAKESPEARE

MurRay, L. y P. (1995). El arte del Renacimiento. Barcelona: Destino.

PeIRCE, C. S. (1974). La ciencia de la semiótica. Buenos Aires: Nueva Visión.

SAlingaR, L. (1986). Dramatic Form in Shakespeare and the Jacobeans. Cambridge University Press.

SERPIERI, A. (1991). «Reading the Signs: Towards a Semiotics of Shakespearean Drama». En Alternative Shakespeares, John Drakakis (ed.), 119-143. London: Methuen.

Todas las citas de obras de Shakespeare están tomadas de la colección The Arden Editions of the Works of William Shakespeare. 